\title{
THYROID
}

\section{Total thyroidectomy versus lobectomy: surgical approach to T1-T2 papillary thyroid cancer}

\author{
Tiroidectomia totale versus emitiroidectomia: approccio chirurgico al carcinoma \\ papillare della tiroide T1-T2
}

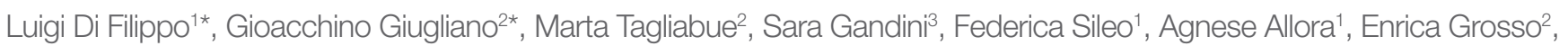 \\ Michele Proh², Veronica Basso ${ }^{2}$, Donatella Scaglione ${ }^{4}$, Marco Federico Manzoni1 ${ }^{1,2 \star}$, Mohssen Ansarinn ${ }^{2 \star \star}$ \\ ${ }^{1}$ Departments of General Medicine and Endocrine Tumor Unit, San Raffaele Scientific Institute, IRCCS, Milano, Italy; ${ }^{2}$ Division of \\ Otolaryngology and Head and Neck Surgery, IEO, European Institute of Oncology, IRCCS, Milan, Italy; ${ }^{3}$ Department of Experimental \\ Oncology, IEO, European Institute of Oncology IRCCS, Milan, Italy; ${ }^{4}$ Division of Data Manager, IEO, European Institute of Oncology, \\ IRCCS, Milan, Italy \\ * Co-first authors L. Di Filippo and G. Giugliano contributed equally to this work. \\ ** Co-last authors M.F. Manzoni and M. Ansarin share co-last authorship.
}

\section{SUMMARY}

The incidence of papillary thyroid carcinoma, which accounts for 80-90\% of all thyroid cancers, has recently been increasing. The current study aimed to compare the oncological and functional outcomes of total thyroidectomy (TT) and thyroid lobectomy (TL). To this end, a retrospective single-centre cohort study involving a tertiary care institution was conducted. Data regarding demographics, clinicopathology and postoperative complications from 586 patients with papillary thyroid cancer treated in a single institution were collected. Cox proportional-hazards models were utilised to determine differences in outcomes stratified according to propensity score. Our data suggested no significant difference in the risk for locoregional recurrence or distant metastasis between TL and TT among patients with pT1-2 pN0 papillary carcinoma. TT plays an important role in improving prognosis among patients with metastatic lymph nodes in the central neck compartment (pN1a) $(p=0.001)$. Moreover, TT had significantly higher rates of postoperative hypocalcaemia and recurrent laryngeal nerve paralysis compared to TL $(\mathrm{p}<0.001$ and $\mathrm{p}=0.02$, respectively).

KEY WORDS: total thyroidectomy, thyroid lobectomy, papillary thyroid cancer, hypocalcaemia, recurrent laryngeal nerve paralysis

\section{RIASSUNTO}

Il carcinoma papillare della tiroide rappresenta l'80-90\% dei tumori tiroidei e la sua incidenza è attualmente in aumento. Vogliamo valutare i risultati oncologici e funzionali del trattamento chirurgico del cancro della tiroide: tiroidectomia totale versus emitiroidectomia. Abbiamo effettuato uno studio monocentrico di coorte storica in un centro di riferimento terziario. Abbiamo raccolto $i$ dati demografici, clinicopatologici e complicanze post operatorie di 586 pazienti trattati nel nostro istituto per carcinoma papillare della tiroide. Sono stati applicati modelli di rischio proporzionale Cox per valutare le differenze nei risultati, stratificandoli con il propensity score. I nostri dati suggeriscono che l'emitiroidectomia non porta ad un aumento del rischio di ricaduta locoregionale né a distanza rispetto alla tiroidectomia totale nei pazienti affetti da carcinoma in stadio T1-2 NO. La tiroidectomia totale riveste un ruolo importante in termini di miglioramento della prognosi nei casi di metastasi linfonodali del comparto centrale del collo ( $p N 1 a)(p=0,001)$. Nella nostra casistica la tiroidectomia totale ha un rischio più elevato di complicanze chirurgiche in termini di ipocalcemia post operatoria e paralisi ricorrenziali $(p<0,001$ e $p=0,02$ rispettivamente).

PAROLE CHIAVE: tiroidectomia totale, emitiroidectomia, carcinoma papillare tiroideo, ipocalcemia, paralisi ricorrenziale
Received: January 15, 2020

Accepted: June, 9, 2020

\section{Correspondence}

Marta Tagliabue

Division of Otolaryngology and Head \& Neck Surgery European Institute of Oncology, via Ripamonti 435, 20141 Milan, Italy

Tel. +3902 57489490. Fax +390294379216

E-mail: marta.tagliabue@ieo.it

Funding

None

Conflict of interest

The Authors declare no conflict of interest.

How to cite this article: Di Filippo L, Giugliano $\mathrm{G}$, Tagliabue $\mathrm{M}$, et al. Total thyroidectomy versus lobectomy: surgical approach to T1-T2 papillary thyroid cancer. Acta Otorhinolaryngol Ital 2020;40:254-261. https://doi. org/10.14639/0392-100X-N0608

๑ Società Italiana di Otorinolaringoiatria e Chirurgia Cervico-Facciale

\section{cc) (i) $\circledast$}

This is an open access article distributed in accordance with the CC-BY-NC-ND (Creative Commons Attribution-NonCommercial-NoDerivatives 4.0 International) license. The article can be used by giving appropriate credit and mentioning the license, but only for non-commercial purposes and only in the original version. For further information: https:// creativecommons.org/licenses/by-nc-nd/4.0/deed.en 


\section{Introduction}

The incidence of papillary thyroid carcinoma (PTC), which accounts for $80-90 \%$ of all thyroid cancers, has currently been increasing due to increased diagnostic scrutiny and better diagnostic technology ${ }^{1}$. The widespread availability and improved sensitivity of neck ultrasonography (US) and fine-needle aspiration cytology (FNAC), accounting partly as overdiagnosis, and effects of environmental and lifestyle changes, may be responsible for such an increase 2,3. The Surveillance, Epidemiology and End Results (SEER) database reported that incidence rates for PTC increased 2.4-fold during the few last decades predominantly among those with low-risk intrathyroidal T1-T2 carcinoma ${ }^{4,5}$. Despite its high prevalence, thyroid cancer is rarely deadly with an excellent prognosis and a 10 -year survival rate exceeding $90 \%{ }^{6-9}$. Unfortunately, disease recurrence and postoperative surgical complications remain very common ${ }^{10}$. No universal agreement on the management of PTCs, especially the smallest lesions, has been established given that confidently differentiating between aggressive and slowly progressing diseases is not yet possible. To date, thyroid surgery has been the main treatment for PTCs. The extent of curative surgery has long been a controversial topic, with evidence for both conservative surgery (lobectomy) and radical surgery (total thyroidectomy). Although the 2009 American Thyroid Association (ATA) guidelines had recommended total thyroidectomy (TT) for PTCs $>1 \mathrm{~cm}$, the recent 2016 ATA guidelines recommend lobectomy alone for low-risk, 1-4 cm PTCs ${ }^{11,12}$. Recent studies have observed that surgery type did not affect patient outcomes and were much more related to cancer intrinsic risk factors or patients themselves ${ }^{13-20}$. Other studies have reported that thyroid lobectomy (TL) had a higher risk for recurrence compared to TT 9,21,22. Furthermore, adverse surgical events, such as hypocalcaemia and recurrent laryngeal nerve injury, are more frequent and severe after TT than after lobectomy alone ${ }^{23,24}$. As confirmed by the latest ATA guidelines, accurate preoperative staging and risk evaluation is crucial to determine the proper surgical approach and post-surgical management ${ }^{12}$. While some potential risk factors, such as histological features, vascular invasion and extrathyroidal extension (ETE), are difficult to evaluate preoperatively, others, like age, sex, familial history, BRAFV600E mutation and lymph node (LN) involvement can be readily assessed preoperatively ${ }^{25-30}$. To date, the role of surgical extension among patients with PTC remains controversial. As such, the present study aimed to compare long-term outcomes of TT and TL among patients with T1-T2 PTC and evaluate postoperative complication rates. To minimise selection bias, various statistical analyses were performed to categorise our cohort according to the presence or absence of lymphadenectomy (central neck dissection) while accounting for prognostic and confounding factors.

\section{Materials and methods}

\section{Study population}

This retrospective single-centre cohort study was approved by the European Institute of Oncology Ethics Committee. From January 1995 to January 2018, a total of 3,013 patients underwent surgical treatment at the Otolaryngology and Head and Neck Surgery Department of the European Institute of Oncology IRCCS, Milan, Italy. Patients $(n=2,424)$ with the following characteristics were excluded: age less than 18 years, benign disease, previous thyroid treatment, mixed-type PTC, tumour size $>4 \mathrm{~cm}$, pT3-pT4 stage, cN1b, distant metastasis, followup $<6$ months and contralateral TL completion performed for reasons other than suspected or proved recurrence. Ultimately, 586 patients with pT1 or pT2 PTC were enrolled and assigned to two groups according to whether they received TT (group; $n=412$ ) or TL (group; $n=174$ ). Patient demographics and surgical and histopathologic details (histological features, lesion size, multifocality and LN metastases) were determined from the IEO electronic archive. To minimise selection bias, we divided our cohort in two groups according to the presence of central neck dissection during surgical planning, considering that most locoregional recurrences (LRRs) involve locoregional cervical lymph nodes.

\section{Patient management}

Preoperative patient evaluation included a complete clinical examination, routine blood tests, laryngeal fibroscopy to determine vocal cord mobility, US to estimate size, possible ETE and LN metastases in the central area (VI level) and FNAC ${ }^{31}$. Most cases underwent FNAC for preoperative diagnosis of PTC, whereas others were diagnosed incidentally through surgical specimens from patients undergoing treatment for a cytologically benign disease.

\section{Surgical approach}

TL was performed among patients with no evidence of ETE, no bilateral carcinoma and a lesion size of $<2 \mathrm{~cm}$ in diameter when FNAC was positive for carcinoma and $>2$ and $<4 \mathrm{~cm}$ when preoperative FNAC was Tyr 2. TT was performed among cases with bilateral carcinoma, oncological lesion $\leq 4 \mathrm{~cm}$, benign lesion $>4 \mathrm{~cm}$, bilateral goiter, 
familial history of thyroid cancer and uncertain contralateral nodules. All surgical approaches were determined through multidisciplinary team decisions with the patient's consent. Clinically node-negative patients underwent prophylactic central neck dissection when thyroid FNAC was Tyr 3, 4, or 5 , as recommended by the multidisciplinary team, or when macroscopic ETEs were detected during preoperative US or following surgery ${ }^{12,32-34}$.

The aforementioned surgical management was standardised at our Institute starting in 2010, during which a more efficient, minimally invasive surgery and systematic use of surgical loupes for all surgeons were introduced.

Radicalisation was proposed when central neck metastasis or ETE were discovered to allow for radioactive iodine treatment (RAIT) in TL cases.

\section{Surgical complications and follow-up}

An analysis of the two most frequent postoperative thyroidectomy complications (i.e., transient or permanent hypocalcaemia and transient or permanent recurrent laryngeal nerve paralysis) was performed. Only euthyroid patients with normal preoperative calcium and PTH levels were included. As suggested by American Association of Clinical Endocrinologists guidelines, hypocalcaemia was defined as a serum albumin-corrected total calcium level lower than $2.1 \mathrm{mmol} / \mathrm{L}(8.5 \mathrm{mg} / \mathrm{dL})$ regardless of signs and symptoms ${ }^{35}$. Permanent hypocalcaemia was defined as requirement of vitamin D and calcium supplementation for more than 12 months after surgery, independent of calcium values ${ }^{35}$. Patients with aggressive cancer features and risk factors, such as pT2 stage and/or central node involvement, underwent RAIT according to current guidelines 12,33,34. The postoperative follow-up included clinical evaluation consisting of physical examination, laryngeal fibroscopy, neck US, iodine-131 scan (for TT) and serum thyroglobulin samples at 6- to 12-month intervals (for TT and TL). Outcomes evaluated included LRR, metastasis occurrences, and mortality. LRR was defined as a new lesion in the thyroidectomy bed or cervical LNs detected through clinical examination with neck US and increased thyroglobulin levels and confirmed using FNAC or histopathological samples from the re-intervention. Metastasis was detected using iodine-131 scans (for TT), computed tomography, or cytology and histology. Recurrence-free survival (RFS) was defined as the time interval, expressed in months, between the first surgery and detection of recurrence (both LRR and distant metastasis).

\section{Statistical analyses}

All analyses comparing the type of thyroidectomy were stratified according to the presence or absence of lymphadenectomy. Categorical variables were presented as relative frequencies (percentages). Continuous variables were reported as median and interquartile range. Categorical variables were compared using Fisher's exact test, while continuous variables were compared using the Wilcoxon signed-rank test. The Kaplan-Meier method was utilised to generate survival curves, which were compared using the log-rank test. To reduce the impact of confounding factors and treatment selection bias, a propensity score was used to identify factors significantly associated with thyroidectomy type. Cox proportional-hazards models were stratified according to the propensity score. All tests were two-sided with a p-value of $<0.05$ considered statistically significant.

\section{Results}

Patient characteristics and surgical technique(s)

Demographics and clinicopathological features of the 586 patients are presented in Table I. Patients had a median age of 48 years [interquartile range (IQR): $39-58$ years], among whom 461 were women $(78.7 \%)$. Multifocality was found in 182 patients (31.1\%). Moreover, 494 patients had pT1 PTC (84.3\%), while 92 had pT2 PTC (15.7\%). Among the 586 patients who satisfied the selection criteria, $412(70.3 \%)$ underwent TT and $174(29.7 \%)$ underwent TL. The median follow-up duration was 58 months (IQR: 24-102 months). None of the patients developed distant metastasis. Significant differences in age [50 (41-59) vs 43 (36-52) years; $p<0.001]$, multifocality $(37.6 \%$ vs $15.5 \%$; $\mathrm{p}<0.001)$ and central neck dissection $(62.1 \%$ vs $47.7 \%$; $\mathrm{p}=0.0012$ ) were observed between the TT and TL groups, respectively, as expected from the pre-surgical studies (Tab. I). No significant differences in sex and pT stage were observed between groups ( $\mathrm{p}=0.52$ and 0.86 , respectively). Central lymphadenectomy was performed in 339 patients (57.8\%). Demographics and clinicopathological features of those who did and did not undergo central lymphadenectomy are summarised in Tables II and III.

Postoperative follow-up of patients who underwent central neck dissection

No deaths related to thyroid disease occurred among patients who underwent central neck dissection. A total of four patients $(1.17 \%)$ developed local relapse (two with LN metastases and two in the contralateral lobe), among whom three underwent TL and one TT. Among those who underwent central lymphadenectomy, significant differences in multifocality (43.4\% vs $13.3 \%$; p < 0.001), central LN metastasis $(42.2 \%$ vs $15.7 \%$; $<<0.001)$ and age $(\mathrm{p}=0.05)$ were found between the TT and TL groups (Tab. II). To evaluate survival curves of TT and TL groups, 
Table I. Prognostic factors according to type of surgery.

\begin{tabular}{|c|c|c|c|c|c|}
\hline & & Lobectomy (LT) & Total Thyroidectomy (TT) & Total & P-value \\
\hline & & $174(100)$ & $412(100)$ & $586(100)$ & \\
\hline \multirow[t]{2}{*}{ pT } & 1 & 146 (83.9) & 348 (84.5) & 494 (84.3) & 0.8653 \\
\hline & 2 & $28(16.1)$ & $64(15.5)$ & $92(15.7)$ & \\
\hline \multirow[t]{2}{*}{ Sex } & Females & $134(77)$ & $327(79.4)$ & $461(78.7)$ & 0.5244 \\
\hline & Males & $40(23)$ & $85(20.6)$ & $125(21.3)$ & \\
\hline \multirow[t]{2}{*}{ Multifocality } & No & $147(84.5)$ & $257(62.4)$ & $404(68.9)$ & $<0.0001$ \\
\hline & Yes & 27 (15.5) & $155(37.6)$ & $182(31.1)$ & \\
\hline \multirow[t]{2}{*}{ Year of surgery } & $\leq 2010$ & $122(70.1)$ & $249(60.4)$ & $371(63.3)$ & 0.0263 \\
\hline & > 2010 & $52(29.9)$ & $163(39.6)$ & $215(36.7)$ & \\
\hline \multirow[t]{2}{*}{ Age } & $<48$ & $117(67.2)$ & $189(45.9)$ & $306(52.2)$ & $<0.0001$ \\
\hline & $\geq 48$ & $57(32.8)$ & $223(54.1)$ & $280(47.8)$ & \\
\hline \multirow[t]{2}{*}{ Lymphadenectomy } & No & $91(52.3)$ & $156(37.9)$ & 247 (42.2) & 0.0012 \\
\hline & Yes & $83(47.7)$ & $256(62.1)$ & $339(57.8)$ & \\
\hline
\end{tabular}

Table II. Central lymphadenectomy group - prognostic factors according to type of surgery.

\begin{tabular}{|c|c|c|c|c|c|}
\hline & & $\begin{array}{l}\text { Lobectomy } \\
\text { (LT) }\end{array}$ & $\begin{array}{l}\text { Total Thyroidectomy } \\
\text { (TT) }\end{array}$ & Total & P-value \\
\hline & & $83(100)$ & $256(100)$ & 339 (100) & \\
\hline \multirow[t]{2}{*}{ pT } & 1 & $77(92.8)$ & 214 (83.6) & $291(85.8)$ & 0.037 \\
\hline & 2 & $6(7.2)$ & 42 (16.4) & 48 (14.2) & \\
\hline \multirow[t]{2}{*}{ Sex } & Females & 59 (71.1) & $194(75.8)$ & $253(74.6)$ & 0.393 \\
\hline & Males & $24(28.9)$ & $62(24.2)$ & $86(25.4)$ & \\
\hline \multirow[t]{2}{*}{ Multifocality } & No & $72(86.7)$ & $145(56.6)$ & 217 (64) & $<0.0001$ \\
\hline & Yes & $11(13.3)$ & $111(43.4)$ & $122(36)$ & \\
\hline \multirow[t]{2}{*}{ Year of surgery } & $\leq 2010$ & $42(50.6)$ & 137 (53.5) & 179 (52.8) & 0.644 \\
\hline & $>2010$ & $41(49.4)$ & $119(46.5)$ & $160(47.2)$ & \\
\hline \multirow[t]{2}{*}{ Age $^{*}$} & $<48$ & $56(67.5)$ & $142(55.5)$ & 198 (58.4) & 0.054 \\
\hline & $\geq 48$ & $27(32.5)$ & $114(44.5)$ & $141(41.6)$ & \\
\hline \multirow[t]{2}{*}{ pN1a } & No & $70(84.3)$ & $148(57.8)$ & 218 (64.3) & $<0.0001$ \\
\hline & Yes & $13(15.7)$ & $108(42.2)$ & $121(35.7)$ & \\
\hline
\end{tabular}

* median value; $p$-values of Chi-square test.

Table III. No central lymphadenectomy group - prognostic factors according to type of surgery.

\begin{tabular}{|c|c|c|c|c|c|}
\hline & & $\begin{array}{l}\text { Lobectomy } \\
\text { (LT) }\end{array}$ & $\begin{array}{l}\text { Total Thyroidectomy } \\
\text { (TT) }\end{array}$ & Total & P-value \\
\hline & & $91(100)$ & 156 (100) & 247 (100) & \\
\hline \multirow[t]{2}{*}{ pT } & 1 & $69(75.8)$ & 134 (85.9) & 203 (82.2) & 0.046 \\
\hline & 2 & $22(24.2)$ & $22(14.1)$ & 44 (17.8) & \\
\hline \multirow[t]{2}{*}{ Sex } & Females & $75(82.4)$ & 133 (85.3) & $208(84.2)$ & 0.555 \\
\hline & Males & $16(17.6)$ & 23 (14.7) & 39 (15.8) & \\
\hline \multirow[t]{2}{*}{ Multifocality } & No & $75(82.4)$ & 112 (71.8) & $187(75.7)$ & 0.056 \\
\hline & Yes & $16(17.6)$ & 44 (28.2) & $60(24.3)$ & \\
\hline \multirow[t]{2}{*}{ Year of surgery } & $\leq 2010$ & $80(87.9)$ & $112(71.8)$ & $192(77.7)$ & 0.003 \\
\hline & > 2010 & $11(12.1)$ & 44 (28.2) & 55 (22.3) & \\
\hline \multirow[t]{2}{*}{ Age $^{*}$} & $<48$ & $61(67)$ & $47(30.1)$ & $108(43.7)$ & $<0.0001$ \\
\hline & $\geq 48$ & 30 (33) & 109 (69.9) & 139 (56.3) & \\
\hline
\end{tabular}

P-values of Chi-square test. 
Table IV. Multivariate logistic models to determine propensity scores used in the Cox models - prognostic factors significantly associated with type of surgery: association between hemi-thyroidectomy vs. thyroidectomy.

\begin{tabular}{|c|c|c|c|c|c|c|}
\hline & & & OR & Low 95\% Cl & High $95 \% \mathrm{Cl}$ & P-values \\
\hline \multirow[t]{3}{*}{ Central lymphadenectomy } & Multifocality & No vs yes & 4.78 & 2.37 & 9.61 & $<0.0001$ \\
\hline & pN & No vs yes & 4.30 & 2.18 & 8.49 & $<0.0001$ \\
\hline & Age & & 0.97 & 0.95 & 0.99 & 0.0127 \\
\hline \multirow[t]{3}{*}{ No central lymphadenectomy } & Multifocality & No vs yes & 2.30 & 1.14 & 4.65 & 0.0204 \\
\hline & Age & & 0.93 & 0.91 & 0.96 & $<0.0001$ \\
\hline & Year of surgery & $>2010$ vs $\leq 2010$ & 0.34 & 0.16 & 0.74 & 0.0063 \\
\hline
\end{tabular}

Cl: Confidence Interval.

multivariate logistic models were created to determine propensity scores using prognostic factors that were significantly associated with type of surgery: multifocality, LN involvements and age (Tab. IV). Our analyses found that RFS rates differed significantly between the TT and TL groups $[\mathrm{p}=0.041$; hazard ratio (HR): $11.127,95 \%$ confidence interval (CI): 1.117-110.8)] (Tab. V, Fig. 1). In particular, this difference was found only among patients with central LN metastasis (pN1a) and not among those with $\mathrm{pN} 0$ ( $\mathrm{p}=0.001$ and 0.16 , respectively) (Figs. 2A, B).

\section{Postoperative follow-up of patients without central neck dissection}

No deaths related to thyroid disease occurred among patients who did not undergo central neck dissection. A total of six patients (2.43\%) developed local relapse (three with lateral neck metastases, two in the contralateral thyroid lobe and one with both lateral neck and contralateral thyroid lobe metastases), among whom three underwent TL and three TT. Among those who did not undergo central lymphadenectomy, significant differences in age ( $p \leq 0.001)$ and year of surgery were observed between the TT and TL groups ( $\mathrm{p}=0.003$ ) (Tab. III). To evaluate survival curves of TT and TL groups, multivariate logistic models were established to determine propensity scores using prognostic factors that were significantly associated with type of surgery: multifocality, year of surgery and age (Tab. IV). Our analyses found no significant difference in RFS between TT and TL groups ( $\mathrm{p}=0.73$; HR: $1.364,95 \%$ CI: 0.228-8.159) (Tab. V; Fig. 2C).

\section{Differences in complications rates between groups}

Serum calcium levels were collected in 419 patients after surgery. Using the previously established definition for hypocalcaemia, $243(58 \%)$ and 22 patients $(5.2 \%)$ were determined to have postoperative transient and permanent hypocalcaemia, respectively. Transient hypocalcaemia was significantly more common in the TT group than in the TL group $(64.9 \%$ vs $19.1 \%$; $p<0.001)$, whereas no significant difference in permanent hypocalcaemia was observed,
Table V. Multivariate Cox proportional hazard models stratified by propensity scores - analyses are carried out in the two groups by lymphadenectomy.

$\begin{array}{lcccc} & \text { HR } & \text { Low } & \text { Up } & \text { P-values } \\ \text { Central lymphadenectomy } & 11.127 & 1.117 & 110.8 & 0.041 \\ \text { No central lymphadenectomy } & 1.364 & 0.228 & 8.159 & 0.733\end{array}$

Hazard ratio (HR) of relapse and 95\% confidence intervals refer to type of surgery: hemithyroidectomy vs total thyroidectomy.

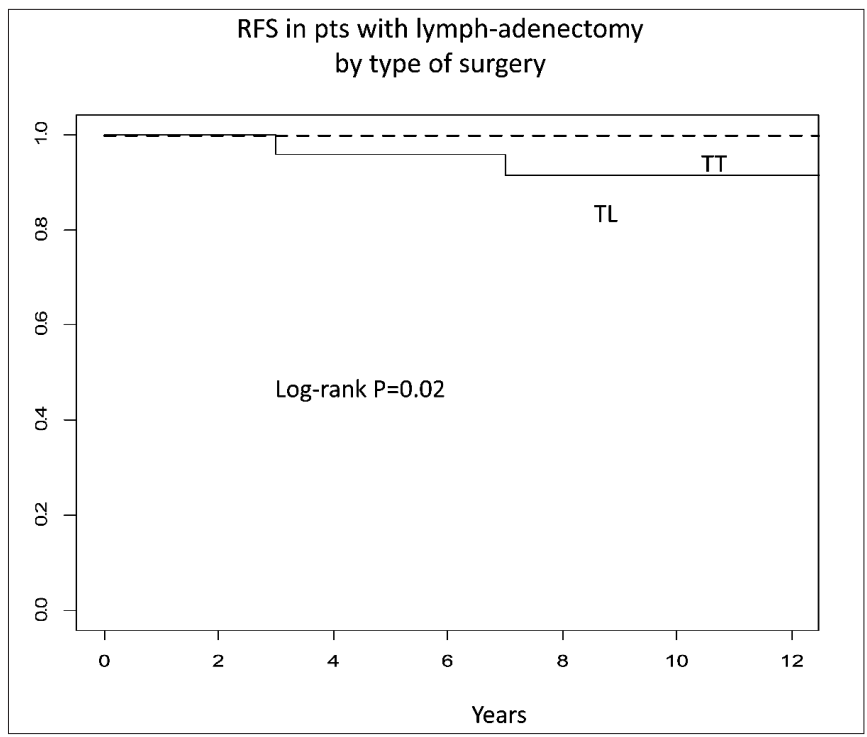

Figure 1. Recurrence-free survival (RFS) in patients receiving lymphadenectomy according to type of surgery: Total Thyroidectomy (TT) vs Thyroid Lobectomy (TL).

perhaps due to the number of subjects evaluated (Tab. VI). More cases of transient recurrent laryngeal nerve paralysis were observed among those who underwent TT than those who underwent TL $(\mathrm{p}=0.02$; Tab. VI). Only two patients developed permanent recurrent laryngeal nerve paralysis, both of whom belonged to the TT group (Tab. VI). One patient needed tracheostomy, which was removed at 4 months after surgery for movement in one vocal cord. The second one reported unilateral permanent vocal cord paralysis without respiratory problems.

No upper laryngeal nerve damage was noted, while none of 

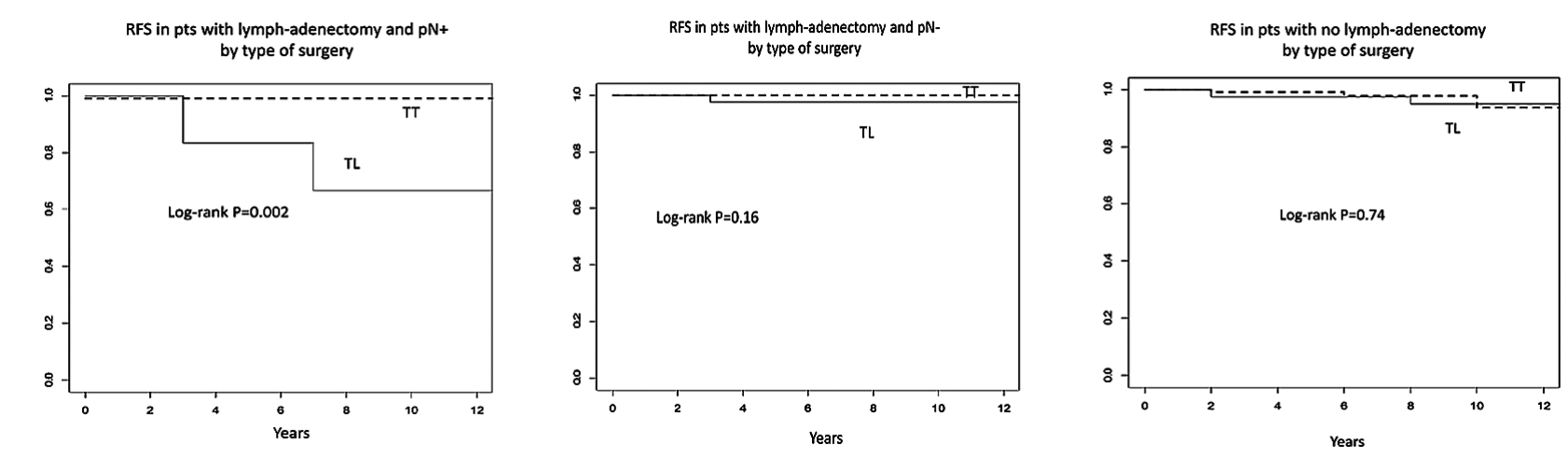

A

B

Figure 2. (A) recurrence-free survival (RFS) in patients receiving lymphadenectomy and pN+ according to type of surgery: Total Thyroidectomy (TT) vs Thyroid Lobectomy (TL); (B) recurrence-free survival (RFS) in patients receiving lymphadenectomy and pN- according to type of surgery: Total Thyroidectomy (TT) vs Thyroid Lobectomy (TL); (C) recurrence-free survival (RFS) in patients no receiving lymphadenectomy according to type of surgery: Total Thyroidectomy (TT) vs Thyroid Lobectomy (TL).

Table VI. Complications by type of surgery.

\begin{tabular}{|c|c|c|c|c|c|}
\hline & & $\begin{array}{l}\text { Lobectomy } \\
\text { (LT) }\end{array}$ & $\begin{array}{c}\text { Total Thyroidectomy } \\
\text { (TT) }\end{array}$ & Total & P-value \\
\hline & & $174(100)$ & $412(100)$ & $586(100)$ & \\
\hline \multirow[t]{2}{*}{ Parathyroidectomy } & No & $165(94.8)$ & $357(86.7)$ & $522(89.1)$ & 0.0037 \\
\hline & Yes & $9(5.2)$ & 55 (13.3) & $64(10.9)$ & \\
\hline \multirow[t]{2}{*}{ Vocal cord transient paralysis } & No & $168(96.6)$ & $376(91.3)$ & $544(92.8)$ & 0.0233 \\
\hline & Yes & $6(3.4)$ & $36(8.7)$ & $42(7.2)$ & \\
\hline \multirow[t]{4}{*}{ Vocal cord permanent paralysis } & No & $6(3.4)$ & $34(8.3)$ & $40(6.8)$ & 0.5541 \\
\hline & Yes & $0(0)$ & $2(0.5)$ & $2(0.3)$ & \\
\hline & & $\begin{array}{l}\text { Lobectomy } \\
\text { (LT) }\end{array}$ & $\begin{array}{c}\text { Total Thyroidectomy } \\
\text { (TT) }\end{array}$ & Total & $\mathrm{p}$-value \\
\hline & & $63(100)$ & $356(100)$ & $419(100)$ & \\
\hline \multirow[t]{2}{*}{ Transient hypocalcaemia } & No & $51(80.9)$ & $125(35.1)$ & $176(42)$ & $<0.0001$ \\
\hline & Yes & $12(19.1)$ & $231(64.9)$ & $243(58)$ & \\
\hline Persistent hypocalcaemia & Yes & $0(0)$ & $22(6.2)$ & $22(5.2)$ & 0.2434 \\
\hline
\end{tabular}

P-values of Chi-square tests.

the patients reported swallowing disorders due to impaired sensitivity during bolus passage.

\section{Discussion}

Despite the increasing incidence of PTC, mortality rates remain constant, while prognosis remains excellent ${ }^{4}$.

The excellent behaviour of this tumour has led to ongoing debates regarding the necessity of surgical management ${ }^{5,8}$. Two large studies by Bilimoria et al. (2007) and Adam et al. (2014) had reached opposite conclusions. Accordingly, Bilimoria et al. found that among 52,173 patients, those with PTC $>1 \mathrm{~cm}$ who underwent conservative surgery exhibited increased rates of recurrence ${ }^{9}$. However, that study had several limitations mainly due to the use of administrative registries from which clinicopathological variables were missing. Conversely, Adam et al., who examined 61,775 patients with 1-4 cm PTC, found that OS was similar between patients who underwent conservative and radical surgery after multivariable adjustment for clinical and pathological factors 14. Supporters of TT underline the lower risk of recurrence, possibility of thyroglobulin administration during followup, and use of I-131 for both diagnostic and therapeutic aims ${ }^{36}$. On the other hand, lobectomy has been preferred for its lower postsurgical morbidity and the absence of lifelong replacement therapy ${ }^{23,24,37}$. Moreover, supporters of lobectomy have stated that several studies found no 
difference in recurrence rates and that patients who develop recurrence can still be successfully treated without increasing disease-specific mortality ${ }^{15}$. The latest ATA guidelines on thyroid carcinoma management concluded that lobectomy alone may be sufficient for low-risk PTC of 1-4 $\mathrm{cm}^{12}$. This indicates that thyroid cancer management must be tailored to each patient according to both stage and risk factors ${ }^{18-20,25-30}$. This approach challenges the predominant role of tumour size in the management of PTC ${ }^{38,39}$. Moreover, studies have proposed that an active surveillance approach toward managing microPTC $(\mathrm{PTC}<1 \mathrm{~cm}$ ) among those with very low-risk (old age, unifocal and well-defined thyroid nodule margins, and no signs of extrathyroidal extension and neck lymph node involvement on US) seems to be a safe and effective alternative to surgical resection ${ }^{40,41}$. The results of our study substantiate the hypothesis that TL does not promote greater risk of recurrence/LRR or distant metastasis among patients with pT1-2 pN0 papillary carcinoma. Our findings showed that TT had a significantly higher rates of postoperative hypocalcaemia and recurrent laryngeal nerve paralysis than TL.

Moreover, 22 patients determined to have permanent hypocalcaemia need continuous replacement therapy to maintain serum calcium levels in the lower reference range. Unfortunately, we have no data on the incidence of osteoporosis and osteoporotic fractures in permanent hypocalcaemia. However, it is not known if the incidence could be influenced by other factors, such as BMI, heredity, sex, age, other conditions, or medical therapies. This should be considered together with an estimate of the financial costs of both treatments given the increasing interest in cost estimation nowadays. A cost-effectiveness analysis conducted at our institution revealed that TL and TT had a direct cost of $€ 3,167$ (2,800-3,200) and $€ 5,099$ $(4,880-5,200)$, respectively ${ }^{42}$. Several limitations of the current study need to be noted. First is the retrospective nature of the analyses with potential confounding variables and treatment selection bias. We note that prospective studies on this disease are very difficult to conduct given the extended life expectancy, extensive follow-up duration, costs associated with such a study and related ethical issues. Another limitation is the small sample size, as well as the short median follow-up duration. On the other hand, this is a single-centre cohort study with complete and accurate medical records. Moreover, the current study utilised propensity scores to reduce the bias of confounding variables related to treatment effect evaluation arising from simply comparing outcomes among those who did and did not receive treatment. This method attempts to do in a retrospective study what randomisation does in a prospective study. TT, on the other hand, plays an important role in the management of metastatic lymph nodes in the central compartment (pN1a), which leads us to highlight the importance of preoperative study to avoid staging errors and reduce the number of subsequent TLs for oncological radicalisation.

\section{Conclusions}

The present study found that TL did not increase the risk for LRR or distant metastasis among those within pT1-2 pN0 PTC and had no effect on RFS. Moreover, TT promoted significantly higher rates of postoperative complications, such as postoperative hypocalcaemia and recurrent laryngeal nerve damage, compared to TL. Additional studies with larger sample sizes and longer follow-up duration would be useful to confirm our data. Although a randomised prospective study would provide much greater statistical power, it may not be feasible considering the characteristics of the disease.

\section{References}

Seib CD, Julie Sosa JA. Evolving understanding of the epidemiology of thyroid cancer. Endocrinol Metab Clin North Am 2019;48:23-35. https://doi.org/10.1016/j.ecl.2018.10.002

2 Pellegriti G, Frasca F, Regalbuto C, et al. Worldwide increasing incidence of thyroid cancer: update on epidemiology and risk factors. J Cancer Epidemiol 2013;2013:965212. https://doi.org/10.1155/2013/965212

3 Marcello MA, Malandrino P, Almeida JF, et al. The influence of the environment on the development of thyroid tumors: a new appraisal. Endocr Relat Cancer 2014;21:T235-54. https://doi.org/10.1530/ERC14-0131

4 Howlader N, Noone AM, Krapcho M, et al. SEER cancer statistics review 1975-2011. Bethesda, Maryland: National Cancer Institute; 2014.

5 Davies L, Welch G. Current thyroid cancer trends in the United States. JAMA Otolaryngol Head Neck Surg 2014;140:317-22. https://doi. org/10.1001/jamaoto.2014.1

6 Gilliland FD, Hunt WC, Morris DM, et al. Prognostic factors for thyroid carcinoma: a population-based study of 15,698 cases from the Surveillance, Epidemiology and End Results (SEER) program 1973 1991. Cancer 1997;79:564-73. https://doi.org/10.1002/(SICI)10970142(19970201)79:3<564:AID-CNCR20>3.0.CO;2-0

7 Adam MA, Pura J, Goffredo P, et al. Impact of extent of surgery on survival for papillary thyroid cancer patients younger than 45 years. J Clin Endocrinol Metab 2015;100:115-21. https://doi.org/10.1210/ jc. 20143039

8 Min Ji Jeon M, Kim HK, Kim EH, et al. Decreasing disease-specific mortality of differentiated thyroid cancer in Korea: a multicenter cohort study thyroid. Endocrinol Metab (Seoul) 2017;32:434-41. https://doi.org/10.1089/thy.2018.0159

9 Bilimoria KY, Bentrem DJ, Ko CY, et al. Extent of surgery affects survival for papillary thyroid cancer. Ann Surg 2007;246:375-81; discussion 381-4. https://doi.org/10.1097/ SLA.0b013e31814697d9

10 Lang BH, Wong CK, Yu HW, et al. Postoperative nomogram for predicting disease-specific death and recurrence in papillary thyroid 
carcinoma. Head Neck 2016;38(Suppl. 1):E1256-63. https://doi. org/10.1002/hed.24201

11 Cooper DS, Doherty GM, Haugen BR, et al. Revised American Thyroid Association management guidelines for patients with thyroid nodules and differentiated thyroid cancer. Thyroid 2009;19:1167-214. https://doi.org/10.1089/thy.2009.0110

12 Haugen BR, Alexander EK, Bible KC, et al. 2015 American Thyroid Association management guidelines for adult patients with thyroid nodules and differentiated thyroid cancer: the American Thyroid Association Guidelines Task Force on thyroid nodules and differentiated thyroid cancer. Thyroid 2016;26:1-133. https://doi. org/10.1089/thy.2015.0020

13 Haigh PI, Urbach DR, Rotstein LE. Extent of thyroidectomy is not a major determinant of survival in low- or high-risk papillary thyroid cancer. Ann Surg Oncol 2005;12:81-9. https://doi.org/10.1007/ s10434-004-1165-1

14 Adam MA, Pura J, Gu L, et al. Extent of surgery for papillary thyroid cancer is not associated with survival. Ann Surg 2014;260:601-7. https://doi.org/10.1097/SLA.0000000000000925

15 Nixon IJ, Ganly I, Patel SG, et al. Thyroid lobectomy for treatment of well differentiated intrathyroid malignancy. Surgery 2012;151:571-9. https://doi.org/10.1016/j.surg.2011.08.016

16 Liu J, Zhang Z, Huang H, et al. Total thyroidectomy versus lobectomy for intermediate-risk papillary thyroid carcinoma: a single-institution matched-pair analysis. Oral Oncol 2019;90:17-22. https://doi. org/10.1016/j.oraloncology.2019.01.010

17 Kuba S, Yamanouchi K, Hayashida N, et al. Total Thyroidectomy versus thyroid lobectomy for papillary thyroid cancer: comparative analysis after propensity score matching: a multicenter study. Int J Surg 2017;38:143-8. https://doi.org/10.1016/j.ijsu.2016.09.083

18 Xing M. Molecular pathogenesis and mechanisms of thyroid cancer. Nat Rev Cancer 2013;13:184-99. https://doi.org/10.1038/ nrc3431

19 Ito Y, McIver B, Besic N, et al. Prognostic factors for thyroid carcinoma originating from follicular cells. J Thyroid Res 2012;2012:920631. https://doi.org/10.1155/2012/920631

20 Xing M, Alzahrani AS, Carson KA, et al. Association between BRAF V600E mutation and mortality in patients with papillary thyroid cancer. JAMA 2013;309:1493-501. https://doi.org/10.1001/ jama.2013.3190

21 Zhang C, Li Y, Jiyu Li, et al. Total thyroidectomy versus lobectomy for papillary thyroid cancer: a systematic review and meta-analysis. Medicine (Baltimore) 2020;99:e19073. https://doi.org/10.1097/ MD.0000000000019073

22 Chan S, Karamali K, Kolodziejczyk A, et al. Systematic review of recurrence rate after hemithyroidectomy for low-risk welldifferentiated thyroid cancer. Thyroid J 2020;9:73-84. https://doi. org/10.1159/000504961

23 Ryu J, Ryu YM, Jung YS, et al. Extent of thyroidectomy affects vocal and throat functions: a prospective observational study of lobectomy versus total thyroidectomy. Surgery 2013;154:611-20. https://doi. org/10.1016/j.surg.2013.03.011

24 Zambeli-Ljepović A, Wang F, Dinan MA, et al. Extent of surgery for low-risk thyroid cancer in the elderly: equipoise in survival but not in short-term outcomes. Surgery 2019;166:895-900. https://doi. org/10.1016/j.surg.2019.05.035

25 Xinyang Li X, Li E, Du J, et al. BRAF mutation analysis by ARMSPCR refines thyroid nodule management. Clin Endocrinol (Oxf) 2019;91:834-41. https://doi.org/10.1111/cen.14079

26 Kuo EJ, Roman SA, Sosa JA. Patients with follicular and Hurtle cell microcarcinoma have compromised survival: a population level study of 22738 patents. Surgery 2013;154:1246-54. https://doi. org/10.1016/j.surg.2013.04.033

27 Vuong HG, Altibi AMA, Duong UNP, et al. Prognostic implication of BRAF and TERT promoter mutation combination in papillary thyroid carcinoma -a meta-analysis. Clin Endocrinol (Oxf) 2017;87:411-7. https://doi.org/10.1111/cen.13413

28 Nilubol N, Boufraqech M, Zhang L, et al. Loss of CPSF2 expression is associated with increased thyroid cancer cellular invasion and cancer stem cell population, and more aggressive disease. J Clin Endocrinol Metab 2014;99:E1173-82. https://doi.org/10.1210/jc.2013-4140

29 Hsiao SJ, Nikiforov YE. Molecular approaches to thyroid cancer diagnosis. Endocr Relat Cancer 2014;21:T301-13. https://doi. org/10.1530/ERC-14-0166

30 Durante C, Tognini S, Montesano T, et al. Clinical aggressiveness and longterm outcome in patients with papillary thyroid cancer and circulating antithyroglobulin autoantibodies. Thyroid 2014;24:113945. https://doi.org/10.1089/thy.2013.0698

31 Giugliano G, Proh M, Gibelli B, et al. Central neck dissection in differentiated thyroid cancer: technical notes. Acta Otorhinolaryngol Ital 2014;34:9-14.

32 Raffaelli M, De Crea C, Sessa L, et al. Prospective evaluation of total thyroidectomy versus ipsilateral versus bilateral central neck dissection in patients with clinically node-negative papillary thyroid carcinoma. Surgery 2012;152:957-64. https://doi.org/10.1016/j. surg.2012.08.053

33 Perros P, Boelaert K, Colley S, et al. Guidelines for the management of thyroid cancer. Clin Endocrinol (Oxf) 2014;81(Suppl 1):1-122. https://doi.org/10.1111/cen.12515

34 Perros P, Colley S, Boelaert K, et al. British Thyroid Association Guidelines for the management of thyroid cancer. Clin Endocrinol (Oxf) 2014;81(Suppl. 1):1-136. https://doi.org/74/5/772

35 Stack BC Jr, Bimston DN, Bodenner DL, et al. American association of clinical endocrinologists and american college of endocrinology disease state clinical review: postoperative hypoparathyroidism definitions and management. Endocr Pract 2015;21:674-85. https:// doi.org/10.4158/EP14462.DSC

36 Schlumberger M, Sherman SI. Approach to the patient with advanced differentiated thyroid cancer. Eur J Endocrinol 2012;166:5-11. https:// doi.org/10.1530/EJE-11-0631

37 Hayward NJ, Grodski S, Yeung M, et al. Recurrent laryngeal nerve injury in thyroid surgery: a review. ANZ J Surg 2013;83:15-21. https://doi.org/10.1111/j.1445-2197.2012.06247.x

38 Ito Y, Kudo T, Kihara M, et al. Prognosis of low-risk papillary thyroid carcinoma patients: its relationship with the size of primary tumors. Endocr J 2012;59:119-25. https://doi.org/10.1507/endocrj.EJ11-0288

39 Tam S, Amit M, Boonsripitayanon M, et al. Effect of tumor size and minimal extrathyroidal extension in patients with differentiated thyroid cancer. Thyroid 2018;28:982-90. https://doi.org/10.1089/ thy. 2017.0513

40 Ito Y, Miyauchi A, Oda H. Low-risk papillary microcarcinoma of the thyroid: a review of active surveillance trials. Eur J Surg Oncol 2018;44:307-15. https://doi.org/10.1016/j.ejso.2017.03.004

${ }^{41}$ Ramundo V, Sponziello M, Rosa Falcone R, et al. Low-risk papillary thyroid microcarcinoma: optimal management toward a more conservative approach. J Surg Oncol 2020;121:958-63. https://doi. org/10.1002/jso. 25848

42 Gibelli B, Dionisio R, Ansarin M. Role of hemithyroidectomy in differentiated thyroid cancer. Curr Opin Otolaryngol Head Neck Surg 2015;23:99-106. https://doi.org/10.1097/MOO.0000000000000142 